\title{
23. MAGNETIC ANISOTROPY IN SERPENTINIZED PERIDOTITES FROM SITE 920: ITS ORIGIN AND RELATIONSHIP TO DEFORMATION FABRICS ${ }^{1}$
}

\author{
Róisín M. Lawrence, ${ }^{2}$ Jeff S. Gee, ${ }^{3}$ and Stephen D. Hurst ${ }^{2}$
}

\begin{abstract}
Anisotropy of magnetic susceptibility (AMS) measurements on serpentinized peridotites from Ocean Drilling Program Site 920 reveal a strong magnetic "fabric," typically characterized by an oblate susceptibility ellipsoid. Curie temperatures and maximum unblocking temperatures near $580^{\circ} \mathrm{C}$, as well as petrographic observations, suggest that magnetite is the sole magnetic carrier in the serpentinites. Because the magnetic mineralogy is dominated by coarse-grained magnetite, the susceptibility ellipsoid should provide a three-dimensional image of the average elongation of magnetite grains or grain clusters. Petrographic studies of three orthogonal thin sections from a limited number of samples indicate that the preferred shape orientation of magnetite grain clusters correlates well with the apparent susceptibility maxima and minima in these planes. The magnetite longaxis preferred orientation is typically within $\sim 20^{\circ}$ of the maximum principal axis of the susceptibility ellipsoid. The close correspondence between the magnetic foliation and the orientation of magnetite-bearing serpentine veins, together with the petrographic evidence for the distribution of magnetite, suggests that the magnetic "fabric" is primarily a reflection of the orientation of these veins. Hence, the AMS ellipsoid may be a more accurate descriptor of the integrated three-dimensional vein orientations than visual orientation measurements made on the split cores.
\end{abstract}

\section{INTRODUCTION}

Drilling at Site $920\left(23^{\circ} 20.3^{\prime} \mathrm{N}, 45^{\circ} 1.0^{\prime} \mathrm{W}\right)$ on the Mid-Atlantic Ridge south of the Kane transform (the MARK area) provided the first extensive recovery of upper mantle rocks exposed at a slowspreading ridge. Holes $920 \mathrm{~B}$ and $920 \mathrm{D}$ penetrated 126 and $206 \mathrm{~m}$, respectively, of serpentinized peridotite and minor discrete diabase intrusions and gabbro intervals (Cannat, Karson, Miller, et al., 1995). Although extensively (commonly $75 \%-90 \%$ ) serpentinized, sufficient relict original minerals and recognizable pseudomorphs allow the determination that most of the peridotites recovered at Site 920 were originally harzburgites, with minor lherzolite intervals. The serpentinized peridotites record a complex history of deformation, with multiple episodes of pseudomorphic replacement by serpentine minerals and serpentine veins superimposed on an earlier high-temperature crystal-plastic fabric.

Shipboard determinations of the anisotropy of magnetic susceptibility (AMS) document the presence of a pronounced magnetic "fabric" (defined by the maximum, intermediate, and minimum axes of the AMS ellipsoid) that is subparallel to both elongate crystals observed in a mesoscopic crystal-plastic fabric and a later anastomosing serpentine vein set (Shipboard Scientific Party, 1995). Although the origin of magnetic anisotropy in serpentinized peridotites may be complex (e.g., MacDonald and Ellwood, 1988), documentation of the relationship between the magnetic and mesoscopic fabrics may ultimately allow the use of AMS data to characterize more subtle variations in the three-dimensional fabric than would be possible from petrographic studies alone. Furthermore, the consistency of the stable remanent inclinations $\left(34^{\circ}, \alpha=1^{\circ}\right.$; where $\alpha$ is the half-angle of the asymmetric $95 \%$ confidence interval; McFadden and Reid, 1982) in samples from Site 920 and the overall similarity of this inclination to that expected from a geocentric axial dipole $\left(\mathrm{GAD}=41^{\circ}\right)$ suggest

'Karson, J.A., Cannat, M., Miller, D.J., and Elthon, D. (Eds.), 1997. Proc. ODP, Sci. Results, 153: College Station, TX (Ocean Drilling Program).

${ }^{2}$ Department of Geology, Duke University, Durham, NC 27708, U.S.A. lawrence@geo.duke.edu

${ }^{3}$ Scripps Institution of Oceanography, La Jolla, CA 92093-0215, U.S.A. that the remanent declinations may provide a first-order estimate of the in situ orientation of structural features in the cores. Indeed, reorientation based on the stable remanent declinations yields a remarkably consistent orientation for the magnetic foliation and the mesoscopic composite foliation (crystal-plastic fabric and late-stage anastomosing serpentine veins); both dip moderately $\left(\sim 30^{\circ}\right)$ toward the median valley axis (Shipboard Scientific Party, 1995; Hurst et al., this volume).

In this study, we present the basic magnetic properties of serpentinized peridotites from Ocean Drilling Program (ODP) Site 920, located in the MARK area, and compare the AMS with the orientation of mesoscopic fabrics and the petrographic distribution of magnetite determined in three orthogonal thin sections from a limited number of samples. Shipboard petrographic observations and magnetic measurements (Shipboard Scientific Party, 1995), as well as additional data presented here, suggest that the remanence in these samples is carried predominantly by relatively coarse-grained magnetite. The orientation of the magnetic susceptibility ellipsoid should therefore provide an integrated three-dimensional representation of the preferred orientation of magnetite grains within these serpentinized peridotites (Tarling and Hrouda, 1993). We find reasonably good agreement between the magnetic fabric (as indicated by AMS) and the petrographic distribution and alignment of magnetite grains or grain clusters in a subset of samples from Site 920.

\section{EXPERIMENTAL METHODS}

The natural remanent magnetization (NRM) and AMS were measured for 144 shipboard and 60 shore-based samples. Discrete sample remanence measurements onboard the JOIDES Resolution were made using a Molspin spinner magnetometer; shore-based measurements were conducted on 2-G Enterprises three-axis cryogenic magnetometers at the Lamont-Doherty Earth Observatory, Scripps Institution of Oceanography, and University of California at Davis paleomagnetism labs. Anisotropy of magnetic susceptibility was measured using a Kappabridge KLY2, using a series of 15 measurement positions for each sample. The eigenvalues and eigenvectors of the sus- 
ceptibility tensor were calculated using the ANI20 program provided by Geofyzika Brno. The magnitude and direction of these eigenvectors are represented by the maximum, intermediate, and minimum susceptibility axes (termed $k_{l}, k_{2}, k_{3}$, respectively). All samples were stepwise demagnetized using either alternating field (AF) or thermal techniques. Best-fit characteristic stable magnetization directions were determined for most samples using principal component analysis (Kirschvink, 1980). For a small number of samples, only the NRM and remanence after demagnetization at $30 \mathrm{mT}$ were reliably determined; the remanence direction after this single demagnetization step provides the best estimate of the characteristic magnetization direction for these samples.

Shipboard paleomagnetic and rock magnetic studies were typically conducted on one minicore sample per core section. The drill core was split vertically along a plane approximately perpendicular to the strike of and parallel to the dip azimuth of the crystal-plastic foliation (Fig. 1). The generally consistent orientation of structural features and magnetic remanence data downcore testifies to the overall success of this approach (fig. 92 in Shipboard Scientific Party, 1995); however, the relative orientation of the split surface of individual cores (including some samples analyzed in detail here) with respect to the composite foliation may vary considerably. Minicores were drilled horizontally from the working half of the core. These minicore samples provide a regular downhole distribution of magnetic data covering the complete range of structural, metamorphic, and lithologic units observed in the cores. Three, orthogonal, polished thin sections were made from 5 minicore samples selected to represent the range of deformation features in the Site 920 cores (Table 1). Ideally, these three orthogonal sections are (1) a vertical section parallel to the maximum dip of the porphyroclastic fabric (the x-y plane), (2) a vertical section perpendicular to the maximum dip azimuth of the porphyroclastic fabric (the $z-x$ plane), and (3) a horizontal section including the sample $y$ and $z$ axes (Fig. 1). A series of photomicrographs were taken for each of the three thin sections to create a montage that covered an area of approximately $20 \times 20 \mathrm{~mm}$. In each montage, the orientations of the long axes of magnetite grain clusters, vein boundaries, and the long axes of orthopyroxene pseudomorphs were measured. Data from each sample were plotted in the form of rose diagrams for each of the orthogonal planes.

Magnetic anisotropy data from the samples are expressed in terms of a suite of parameters suggested by Tarling and Hrouda (1993) to describe AMS properties without the potential bias produced by large variations in bulk susceptibility within a suite of rocks. The shape parameter $(T$; where $-1<T<1)$ is the preferred parameter for the description of the susceptibility ellipsoid shape, as it incorporates all three principal susceptibilities (Jelinek, 1981; Tarling and Hrouda, 1993). $T$ effectively describes the shape of the magnetic anisotropy ellipsoid independent of the amount of magnetic anisotropy. $T=+1$ corresponds to perfectly oblate ellipsoids and $T=-1$ corresponds to perfectly prolate ellipsoids. The corrected degree of magnetic anisotropy, $P_{j}$, is used to describe the amount of magnetic anisotropy.

\section{RESULTS OF MAGNETIC MEASUREMENTS}

The range of NRM intensities for the full suite of serpentinized peridotites $(\mathrm{n}=240)$ sampled from Site 920 is large $(0.1-41.0 \mathrm{~A} / \mathrm{m}$; Fig. 2A). The mean intensity, $11.8 \mathrm{~A} / \mathrm{m}$, is also very high with the majority of samples having intensities greater than $8 \mathrm{~A} / \mathrm{m}$. These magnetization values are similar to those of ocean-floor basalts of comparable age. For example, a recent compilation of Deep Sea Drilling Project and ODP data suggests that Brunhes-age extrusive rocks have an average magnetization of 7-20 A/m (Johnson and Pariso, 1993). The high NRM intensities of Site 920 serpentinites indicate that such rocks cannot be excluded as a possible source of (at least local) magnetic anomalies. The NRM intensities from Site 920 are almost an order of magnitude higher than those from serpentinites

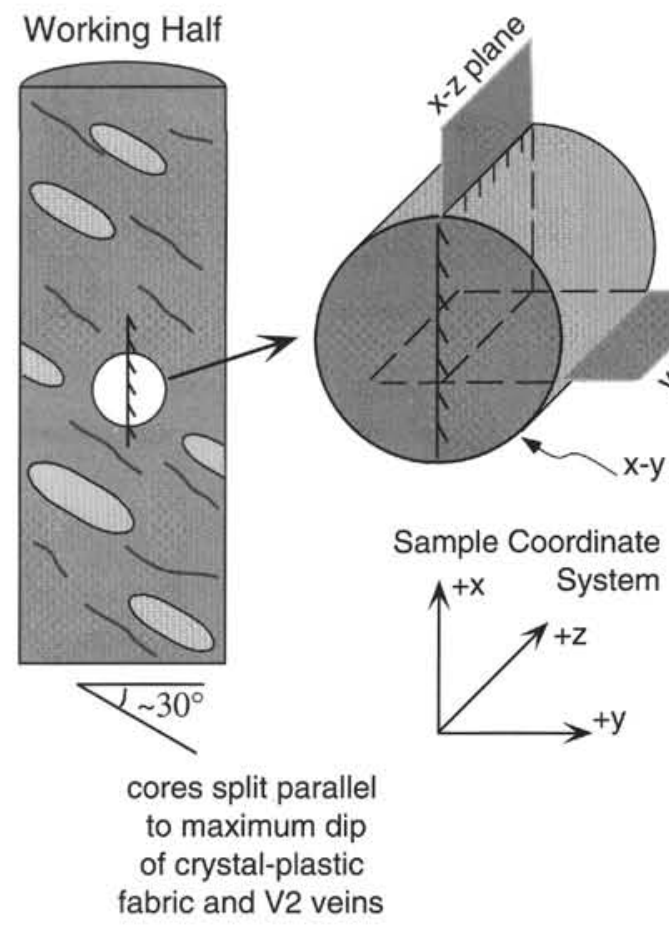

Figure 1. Schematic description of the orthogonal coordinate system used during this study. The cores were split approximately parallel to the maximum dip of the crystal-plastic fabric. A minicore was drilled horizontally into the face of the working half of the core as shown. The coordinate system used for description of the thin sections and AMS results is based upon the minicore axes.

recovered at Site 670 , only $25 \mathrm{~km}$ to the south (Detrick, Honnorez, Bryan, Juteau, et al., 1988). Koenigsberger ratios (the ratio of remanent to induced magnetization, Q) calculated for Site 920 serpentinites range from 1 to 9 , with a mean value of $4.9 \pm 1.8$ (calculated using the International Geomagnetic Reference Field [IGRF] field value for the MARK area of $30.62 \mathrm{~A} / \mathrm{m}$ ). These values indicate that the remanent magnetizations from the serpentinites could contribute significantly to the overall anomaly magnetizations locally. Unaltered peridotites have essentially no primary magnetic minerals and will therefore not have a magnetic remanence. Magnetite in the Site 920 rocks results from alteration and serpentinization processes; hence, the stable remanence directions are not representative of initial formation, but rather reflect the ambient field at the time of magnetite formation associated with initial serpentinization and/or later stage magnetite growth during subsequent episodes of serpentine vein formation.

Both $\mathrm{AF}$ and thermal demagnetization data show that serpentinized peridotites from Site 920 have a consistent univectorial remanence. Because core pieces may rotate after being drilled, the measured magnetic declination cannot be directly referenced to a geographic reference frame. However, the inclinations of the characteristic magnetization are generally between $33^{\circ}-40^{\circ}$ (Figs. $2 \mathrm{~A}, 2 \mathrm{C}$ ), a close approximation to the predicted GAD inclination $\left(41^{\circ}\right)$ in the MARK area. All samples have normal polarity magnetizations. The location of Site 920 on the western flank of the median valley strongly indicates that the consistent normal polarity remanence was acquired sometime during the Brunhes $(0-0.78 \mathrm{Ma}$; Cande and Kent, 1992).

Both petrographic observations and magnetic characteristics suggest that relatively coarse-grained magnetite is the dominant magnetic phase in Site 920 peridotites. Curie temperatures and maximum unblocking temperatures near $580^{\circ} \mathrm{C}$ suggest that Ti-free magnetite is the dominant remanence carrier in these serpentinized peridotites 
A

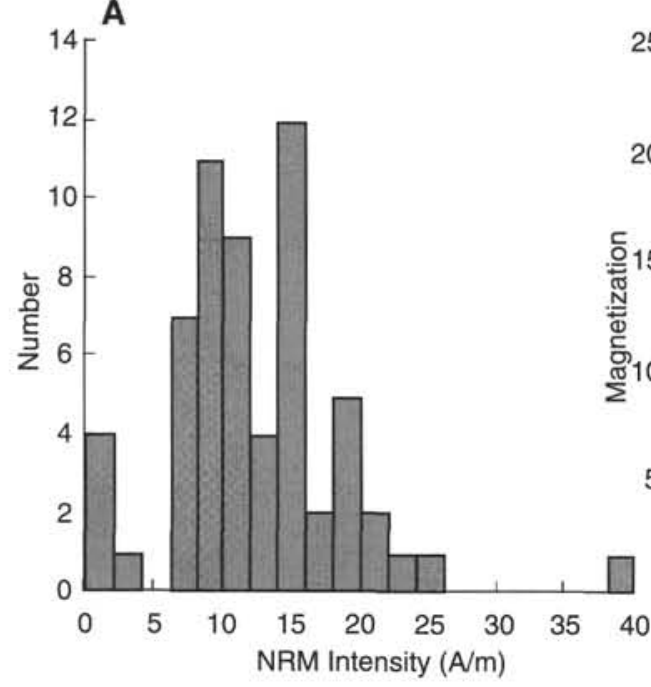

B

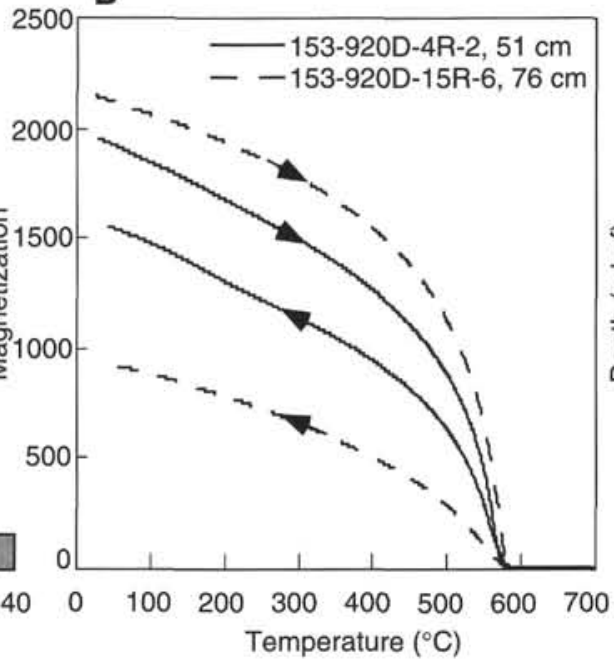

C

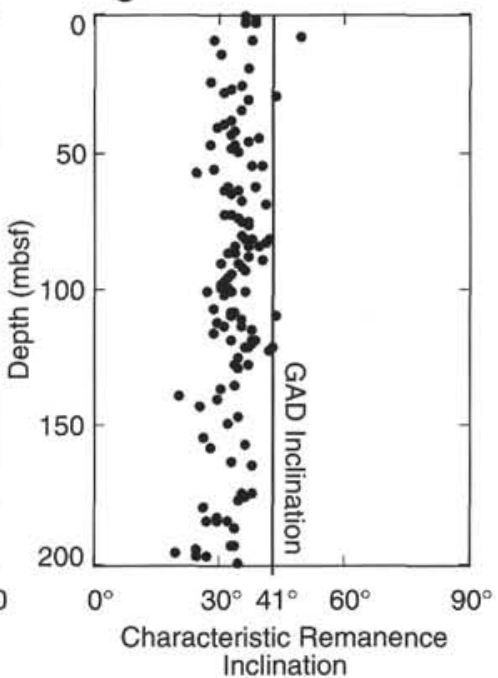

Figure 2. Summary of Site 920 paleomagnetic results. A. Natural remanent magnetization histogram, showing the wide range of NRM intensities recorded (0.1$41 \mathrm{~A} / \mathrm{m})$ and the high average intensity $(11.8 \mathrm{~A} / \mathrm{m})$. B. High-field magnetization vs. temperature for two selected peridotite samples. Curie temperatures of $580^{\circ} \mathrm{C}$ are indicative of magnetite as the main magnetic carrier. Both samples were heated in air at a rate of $25^{\circ} \mathrm{C} / \mathrm{min}$ in a field of approximately $150 \mathrm{mT}$. C. Downhole characteristic inclinations in Hole $920 \mathrm{D}$, showing consistent inclinations, with an inclination-only mean of $34^{\circ}$, only slightly shallower than the GAD inclination of $41^{\circ}$ at Site 920 .

(Fig. 2B). This inference is also supported by the relatively low fields $(<0.2 \mathrm{~T})$ required to achieve saturation isothermal remanence (Shipboard Scientific Party, 1995). Furthermore, the low stability to AF demagnetization (most samples have median destructive fields $[\mathrm{MDF}]<10 \mathrm{mT}$ ) qualitatively suggests a multidomain remanence carrier. As a strong inverse correlation exists between the MDF and magnetic grain size inferred from hysteresis parameters for peridotite samples from ODP Hole 670A in the MARK area (Bina and Henry, 1990), the demagnetization behavior of serpentinized peridotites from Site 920 is consistent with the presence of coarse-grained magnetite as the dominant magnetic carrier. As the susceptibility of coarse-grained (multidomain) magnetite is controlled primarily by the grain shape (Potter and Stephenson, 1988), we infer that the AMS ellipsoid of samples studied here describes the average shape or distribution anisotropy of the magnetite grains in a sample (Tarling and Hrouda, 1993; Hargraves et al., 1991; Stephenson, 1994).

Anisotropy of magnetic susceptibility measurements made on all the serpentinized peridotites show the majority of samples to be strongly anisotropic, with up to $33 \%$ difference in susceptibility between the minimum and maximum directions for any given sample. The large distribution of $P_{j}(1.0114-1.4019)$ highlights the wide range of magnetic anisotropy developed within the serpentinized peridotites. The magnetic fabric in the serpentinites can be characterized by either the shape parameter, $T$, or the relationship between $L$ $\left(k_{i} / k_{2}\right)$ and $F\left(k_{2} / k_{3}\right)$ using a Flinn-type analysis (Cannat, Karson, Miller, et al., 1995). A Flinn-type plot of $L$ vs. $F$ shows that the AMS ellipsoids cover a wide range of shapes, including both strongly oblate and strongly prolate ellipsoids (Fig. 3). The shape parameter, $T$, also demonstrates this wide spread in ellipsoid shapes, with the majority of samples exhibiting oblate susceptibility ellipsoids (Fig. 4). Although $77 \%$ of all samples have oblate susceptibility ellipsoids $(T\rangle$ 0.1 ), only $20 \%$ of the samples have prolate ellipsoids where $T<-0.1$. Susceptibility ellipsoids for which $-0.1<T<0.1$ are termed neutral, following Jelinek (1981). We note, however, that the principal susceptibilities are statistically distinct in all cases, and that samples for which $-0.1<T<0.1$ might better be classified as triaxial. Samples with $P_{j}<1.2$ exhibit a wide range of susceptibility ellipsoid shapes, whereas more anisotropic samples $\left(P_{j}>1.2\right)$ exhibit exclusively oblate magnetic fabrics (Fig. 4).

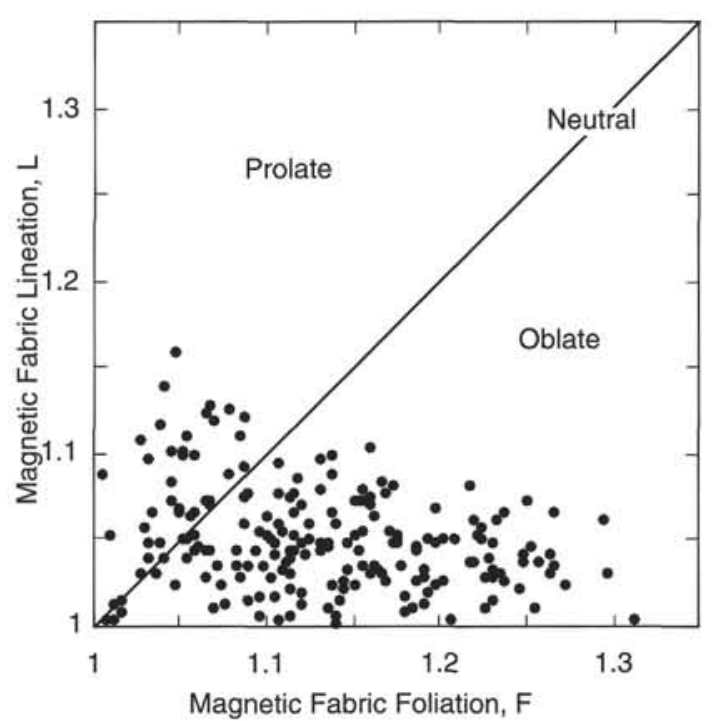

Figure 3. Flinn-type diagram of magnetic properties, $L$ (ratio of $K_{\max }$ to $K_{i n t}$ ) vs. $F$ (ratio of $K_{\text {int }}$ to $K_{\max }$ ). The data show a large scatter in magnetic fabrics, with the majority of the data tending toward oblate fabrics; $<20 \%$ of the samples measured have neutral or prolate susceptibility ellipsoids.

The high average degree of magnetic anisotropy $\left(P_{j}=1.1612\right)$ of the serpentinized peridotites from Site 920 raises the possibility that the remanent magnetization may have been deflected from the ambient field direction. Although the stable remanent inclinations from Site 920 are broadly similar to the expected GAD inclination for the MARK area, the mean inclination $\left(34^{\circ}, \mathrm{n}=200, \alpha=1^{\circ}\right.$; calculated using the method of McFadden and Reid, 1982) is statistically distinct from either the dipole $\left(41^{\circ}\right)$ or the present IGRF inclination $\left(\sim 42^{\circ}\right)$. Acquisition of a thermoremanent magnetization may be deflected in rocks having a significant magnetic anisotropy ( 5\% magnetic anisotropy or $P_{j}=1.09$ may lead to $3^{\circ}$ remanence deflection; Stacey and Banerjee [1974]). However, the relevance of such remanence deflection to (thermo)chemical remanence acquired during al- 


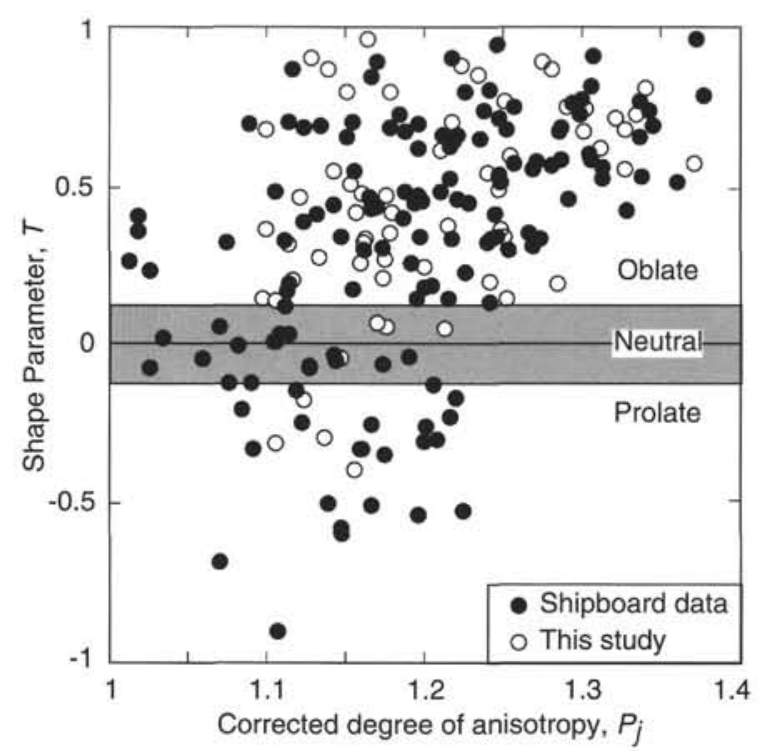

Figure 4. Degree of magnetic anisotropy, $P_{j}$, vs. magnetic fabric shape parameter, $T$, for Site 920 serpentinites. At lower degrees of anisotropy $\left(P_{j}<\right.$ 1.2) there is a large variation in susceptibility ellipsoid shape; however, as the degree of anisotropy increases $\left(P_{j}>1.2\right)$, the magnetic fabric tends toward strongly oblate.

teration of these serpentinized peridotites is uncertain. The magnitude of any deflection, and the resulting effect on both the measured declination and inclination, will be controlled by the precise angular relationship between the applied field and the susceptibility ellipsoid.

\section{RESULTS OF PETROGRAPHIC MEASUREMENTS}

Serpentinized peridotites from Site 920 preserve a complex history of deformation, with the development of a high-temperature crystal-plastic composite foliation and subsequent brittle deformation recorded by up to five generations of veins (Shipboard Scientific Party, 1995). The earliest pervasive mesoscopic fabric in the serpentinites is a crystal-plastic foliation most clearly defined by the elongation of orthopyroxene pseudomorphs set in a matrix of recrystallized and variably altered olivine and orthopyroxene. Orthopyroxene pseudomorph elongation is variable in the cores (for details, see Cannat, Karson, Miller, et al., 1995). The majority of pseudomorphs in the cores exhibits aspect ratios approximating 1.5-1.8:1. The orientation of all mesoscopic fabric elements is reported as apparent dips as measured in the split surface of the core (the sample $x-y$ plane). This plane is generally subparallel to the dip of mesoscopic composite foliation. However, there is significant variability in pseudomorph elongation, ranging from equant to highly elongate (aspect ratios approaching 8:1; Shipboard Scientific Party, 1995). This porphyroclastic fabric has a constant dip of approximately $30^{\circ}$ throughout the core, regardless of the magnitude of the pseudomorph elongation. Alteration of primary olivine has formed a dense network of serpentine \pm magnetite and iron oxide minerals in narrow veinlets $(<0.05 \mathrm{~mm}$ wide) through the cores, termed "serpentine mesh texture." These veinlets mimic the earlier high-temperature crystal-plastic foliation, and together these two features comprise the dominant mesoscopic composite foliation in the core.

There are a number of generations of veins developed in the serpentinized peridotites from Site 920 (Shipboard Scientific Party, 1995). These include discrete magmatic veins (V0 or MV) as well as an early generation of serpentine + actinolite \pm chlorite \pm talc veins (V1) that typically cut the dominant crystal-plastic foliation at a high angle. These two vein sets contain little or no magnetite, and conse- quently would not be expected to contribute to the overall AMS results. The most common vein set (termed V2) occurs as a network of thin (up to $1 \mathrm{~mm}$ ), anastomosing, white and black serpentine + magnetite veins, either parallel or subparallel to the crystal-plastic foliation. Intensity of V2 veining is variable throughout the core; however, few intervals have no V2 development. Magnetite is observed primarily in association with the V2 veins, hence a large proportion of the AMS signature is believed to originate from preferred orientation of magnetite within these veins. The angular relationship between the two fabric elements (magnetic [AMS] and mesoscopic [V2 veins]) rarely exceeds $20^{\circ}$ (the apparent dip in the cut face [x-y plane] of the core). Later vein sets (V3-V5) are characterized by an assemblage of serpentine \pm carbonate \pm pyrite \pm clay minerals. Although small amounts of magnetite may be present in these late-stage veins, they are unlikely to contribute significantly to the magnetic susceptibility anisotropy of the samples.

Five samples from Hole 920D were subjected to detailed petrographic study to examine the relationship between the magnetic fabric (as inferred from AMS) and the orientation of mesoscopic fabric elements and the petrographic distribution of magnetite. These samples were chosen to represent the more common relationships observed between the two dominant rock fabrics (the composite crystalplastic foliation and V2 veins) and the range of magnetic anisotropy characteristics present (Tables 1,2 ). Both rock fabrics are pervasive throughout the cores, varying in intensity and in their angular relationship. The magnetic anisotropy is high throughout all the cores, however the magnitude and ellipsoid shape are variable.

The high degree of magnetic anisotropy of the serpentinized peridotites is presumably the result of an overall preferred dimensional orientation of magnetite grains that formed since the onset of serpentinization, although a number of different pathways are available for production of magnetite (Toft et al., 1990). Magnetite in the Site 920 serpentinized peridotites occurs in five distinct locations: (1) as small almost equant grains within the elongate orthopyroxene pseudomorphs that define the high-temperature crystal-plastic foliation, and (2) in a mesh network throughout the altered olivine mass of the serpentinites (Pl. 1, Fig. 1), (3) within V2 veins in trails perpendicular to the vein boundaries (Pl. 1, Fig. 2), (4) along the boundaries of the lowtemperature V2 serpentine veins (P1. 1, Fig. 3), and (5) along fractures (which generally parallel V2 veins locally) in chrome spinel grains (Pl. 1, Fig. 4).

The highest proportion (both in number and size of individual grains) of magnetite occurs as highly elongate grain clusters subparallel to and along the margins of the walls of the V2 veins. Individual grains along the vein boundaries are commonly perpendicular to the boundaries and have a different long-axis orientation than the cumulative grain clusters. The magnetic anisotropy is the result of the integration of individual grain orientations and the interactions of adjacent grains over the entire sample volume (Hargraves et al., 1991; Stephenson, 1994) and hence should reflect grain-cluster orientations rather than individual grains. Serpentine fibers and magnetite trails within the veins are both apparently orthogonal to the vein margins, in all three thin sections for each sample studied, suggesting that these are pure extensional features.

Petrographic analysis of magnetite grain clusters was performed in three orthogonal planes using oriented thin sections taken from each of the five minicores following determination of the magnetic anisotropy. Orientation analyses were conducted in $10^{\circ}$ increments, recording the number of grain clusters with long axes in each increment. The data show that each sample generally has two planes with a narrow distribution of magnetite grain-cluster long-axes, whereas the third plane has a broad distribution with no apparent preferred orientation. This relationship is most clearly seen in Sample 153-920D14R-3, 91-94 cm, or Sample 15R-3, 96-99 cm, but is apparent in most of the samples (Fig. 5). This is consistent with the suggestion that the overall magnetite preferred dimensional orientation is represented by an oblate ellipsoid similar to the AMS ellipsoid. The appar- 
Table 1. AMS data for the samples studied in the three orthogonal sections.

\begin{tabular}{|c|c|c|c|c|c|c|c|c|c|c|c|}
\hline \multirow[b]{3}{*}{$\begin{array}{l}\text { Core, section, } \\
\text { interval }(\mathrm{cm})\end{array}$} & \multirow[b]{3}{*}{$P_{j}$} & \multirow[b]{3}{*}{$T$} & \multicolumn{9}{|c|}{ Susceptibility ellipsoid } \\
\hline & & & \multicolumn{3}{|c|}{$K_{\max }$} & \multicolumn{3}{|c|}{$K_{\text {int }}$} & \multicolumn{3}{|c|}{$K_{\min }$} \\
\hline & & & $\begin{array}{l}\text { Magnitude } \\
\left({ }^{\circ}\right)\end{array}$ & $\begin{array}{c}\text { Trend } \\
\left({ }^{\circ}\right)\end{array}$ & $\begin{array}{l}\text { Plunge } \\
\left({ }^{\circ}\right)\end{array}$ & $\begin{array}{l}\text { Magnitude } \\
\left(^{\circ}\right)\end{array}$ & $\begin{array}{c}\text { Trend } \\
\left({ }^{\circ}\right)\end{array}$ & $\begin{array}{l}\text { Plunge } \\
\left({ }^{\circ}\right)\end{array}$ & $\begin{array}{l}\text { Magnitude } \\
\left(^{\circ}\right)\end{array}$ & $\begin{array}{c}\text { Trend } \\
\left({ }^{\circ}\right)\end{array}$ & $\begin{array}{l}\text { Plunge } \\
\left({ }^{\circ}\right)\end{array}$ \\
\hline \multicolumn{12}{|l|}{ 153-920D- } \\
\hline $4 R-2,51-54$ & 1.0809 & 0.3708 & 0.3468 & 256.9 & 46.1 & 0.3369 & 162.0 & 4.6 & 0.3163 & 67.6 & 43.5 \\
\hline $14 \mathrm{R}-2,35-38$ & 1.1960 & 0.4917 & 0.3627 & 49.1 & 29.8 & 0.3437 & 216.1 & 59.6 & 0.2935 & 315.8 & 5.6 \\
\hline $14 \mathrm{R}-3,91-94$ & 1.1241 & -0.0424 & 0.3563 & 255.6 & 59.6 & 0.3322 & 117.9 & 23.4 & 0.3115 & 19.7 & 18.2 \\
\hline isR-3, 96-99 & 1.1673 & 0.7078 & 0.3561 & 35.0 & 35.4 & 0.3468 & 181.5 & 49.6 & 0.2971 & 292.5 & 17.0 \\
\hline $15 \mathrm{R}-6,76-79$ & 1.1323 & 0.3279 & 0.3552 & 223.9 & 45.8 & 0.3381 & 126.7 & 7.0 & 0.3067 & 30.0 & 43.4 \\
\hline
\end{tabular}

Table 2. Petrofabric development for the samples studied in three orthogonal sections.

\begin{tabular}{|c|c|c|c|c|c|}
\hline \multirow[b]{3}{*}{$\begin{array}{l}\text { Core, section, } \\
\text { interval }(\mathrm{cm})\end{array}$} & \multirow[b]{3}{*}{$\begin{array}{l}\text { AMS } \\
\text { ellipsoid }\end{array}$} & \multicolumn{4}{|c|}{ Deformation } \\
\hline & & \multicolumn{2}{|c|}{$\mathrm{V} 2$} & \multicolumn{2}{|c|}{ Crystal-plastic foliation } \\
\hline & & Intensity & $\begin{array}{c}\text { Orientation } \\
\left({ }^{\circ}\right)\end{array}$ & $\begin{array}{l}\text { Orthopyroxene } \\
\text { elongation }\end{array}$ & $\begin{array}{c}\text { Orientation } \\
\left({ }^{\circ}\right)\end{array}$ \\
\hline \multicolumn{6}{|l|}{ 153-920D- } \\
\hline $4 \mathrm{R}-2,51-54$ & Oblate & Strong & 30 & $1.6: 1$ & 30 \\
\hline $14 \mathrm{R}-2,35-38$ & Moderately oblate & Moderate & $\sim 30$ & $1.6: 1$ & 30 \\
\hline $14 \mathrm{R}-3,91-94$ & Neutral & None & NA & $1.2: 1$ & $\sim 30$ \\
\hline $15 R-3,96-99$ & Strongly oblate & Strong & 30 & $1.6: 1$ & 30 \\
\hline $15 \mathrm{R}-6,76-79$ & Oblate & Moderate & Horizontal & $1.6: 1$ & $\sim 30$ \\
\hline
\end{tabular}

Note: $\mathrm{NA}=$ not applicable.

ent maximum and minimum susceptibilities were calculated in each of the orthogonal thin-section planes to facilitate comparison with the petrographic observations. The magnitude and direction of the projected maximum and minimum susceptibility ellipsoid components in each plane are given in Table 3.

The majority of the serpentinized peridotites from Site 920 has a well-developed crystal-plastic foliation evident in hand specimen. Low-temperature serpentinization characterized by anastomosing V2 veins approximately parallels this crystal-plastic foliation through much of the core, as illustrated by Samples 153-920D-14R-2, 35-38 $\mathrm{cm}$, and $4 \mathrm{R}-2,51-54 \mathrm{~cm}$. Both samples have V2 veins subparallel to a moderately developed crystal-plastic fabric (pseudomorph aspect ratios of $1.6: 1$ ), which dips $\sim 30^{\circ}$. Sample $14 \mathrm{R}-2,35-38 \mathrm{~cm}$, has a higher degree of anisotropy $\left(P_{j}=1.1690\right)$ than Sample 4R-2, 51-54 $\mathrm{cm}\left(P_{j}=1.0809\right)$. Petrographic analysis of magnetite orientation in both samples shows a strong preferred orientation in magnetite in the $x-y$ and $y-z$ planes and a close correspondence with the apparent maximum susceptibility direction in these planes. The $z-x$ planes have a more diffuse array of magnetite orientations that is less clearly related to the projected susceptibility maxima and minima.

Sample 153-920D-14R-3, 91-94 cm $\left(P_{j}=1.1241\right)$, is the least deformed in hand specimen of the samples in this study and exhibits only minor development of V2 veins, which are anastomosing around orthopyroxene pseudomorphs. The orthopyroxene pseudomorphs are only slightly elongated, with aspect ratios of $1.2: 1$ in the $\mathrm{x}-\mathrm{y}$ plane. Both deformational fabrics have apparent dips of $\sim 30^{\circ}$ in the $\mathrm{x}-\mathrm{y}$ plane. In the $\mathrm{x}-\mathrm{y}$ plane magnetite is predominantly observed within the mesh network with few V2 veins. Petrographically, the magnetite grains within the mesh network have a poorly defined cumulative preferred long-axis orientation, although the susceptibility ellipsoid apparent maximum direction is well within this field, further constraining the preferred dimensional orientation of magnetite within this sample. Both remaining sections from this sample have a relatively well defined preferred magnetite orientation, with maxima that lie within $\sim 15^{\circ}$ of the apparent susceptibility maxima in these planes.

Sample 153-920D-15R-3, 96-99 cm, has a relatively high degree of magnetic anisotropy $\left(P_{j}=1.1673\right)$, and is characterized by minor development of the high-temperature crystal-plastic foliation and a high V2 vein density. Orthopyroxene pseudomorphs (defining the crystal-plastic foliation) have aspect ratios of 1.3:1, the long axes of the pseudomorphs have an apparent dip of $30^{\circ}$ in the $\mathrm{x}-\mathrm{z}$ plane. V2 veins are pervasive in the 20 -cm interval from which this sample was taken. The veins dip $\sim 30^{\circ}$ in the core, approximately the same orientation as the crystal-plastic foliation.

The final sample (Sample 153-920D-15R-6, 76-79 cm) is one in which the crystal-plastic foliation dips approximately $30^{\circ}$ and that has V2 veins that are subhorizontal. Petrographic analyses support the macroscopic observations that the V2 veins and the orthopyroxene elongation directions have an angular offset of $\sim 20^{\circ}$. Both the $\mathrm{x}-$ $y$ and $y-z$ planes show a strong magnetite preferred orientation, which corresponds closely to the apparent susceptibility maxima in these two planes. The distribution of magnetite grains in the $\mathrm{x}-\mathrm{z}$ plane does not agree well with the projected susceptibility values, despite the significant contrast between the apparent susceptibility maximum $(0.3509)$ and minimum $(0.3116)$ in this plane.

\section{DISCUSSION}

The above results indicate a reasonable agreement between AMS and the petrographic distribution of magnetite in Site 920 serpentinized peridotites. Petrographic alignment of magnetite grain clusters is generally subparallel to the apparent maximum susceptibility direction as calculated from the susceptibility ellipsoid (Fig. 5). For example, we note that the three orthogonal sections that exhibit the highest degree of magnetic anisotropy (the $x-y$ plane for Sample 153920D-14R-2, $35 \mathrm{~cm}$, and the $\mathrm{x}-\mathrm{y}$ and $\mathrm{y}-\mathrm{z}$ planes for Sample 15R-3, 96 $\mathrm{cm}$ ) all have a preferred magnetite orientation essentially coincident with the apparent susceptibility maxima in these planes. In contrast, sections with a low susceptibility contrast (e.g., the $\mathrm{x}-\mathrm{z}$ plane for Sample 15R-3, $96 \mathrm{~cm}$ ) tend to exhibit the poorest correlation between the AMS ellipsoid and the petrographically determined magnetite distribution, as might be expected.

The general correspondence of the AMS results and petrographic distribution of magnetite and the volumetric abundance of magnetite in V2 veins suggest that the magnetic fabric primarily reflects the distribution and average orientation of V2 veins. This inference is supported by the overall consistency between the average orientation of the poles to the V2 vein set and the poles to the magnetic foliation for 
$x-y$ plane

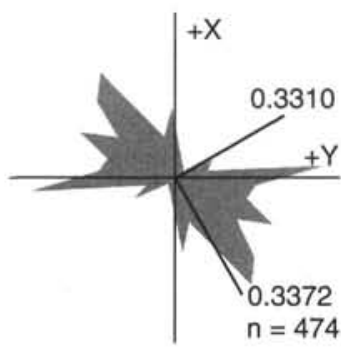

153-920D-4R-2, $51 \mathrm{~cm}$

$\begin{array}{ll}\text { Kmax } & 0.3468 \\ \text { Kint } & 0.3369 \\ \text { Kmin } & 0.3163\end{array}$

y-z plane
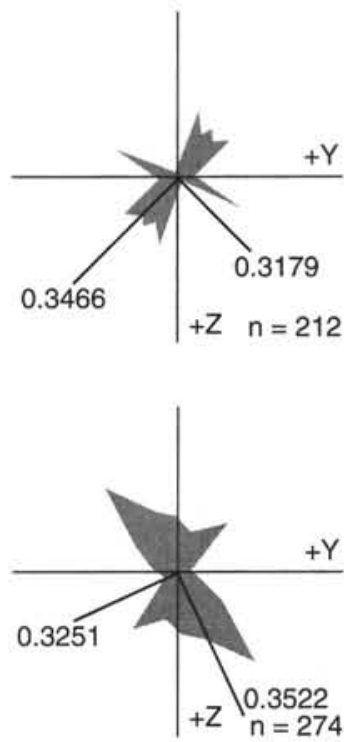

$n=346$

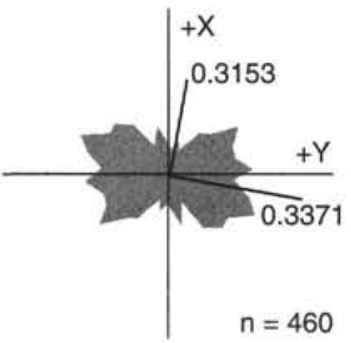

153-920D-14R-3, $91 \mathrm{~cm}$

$\begin{array}{ll}\text { Kmax } & 0.3563 \\ \text { Kint } & 0.3322\end{array}$

$\begin{array}{ll}\text { Kint } & 0.3322 \\ \text { Kmin } & 0.3115\end{array}$
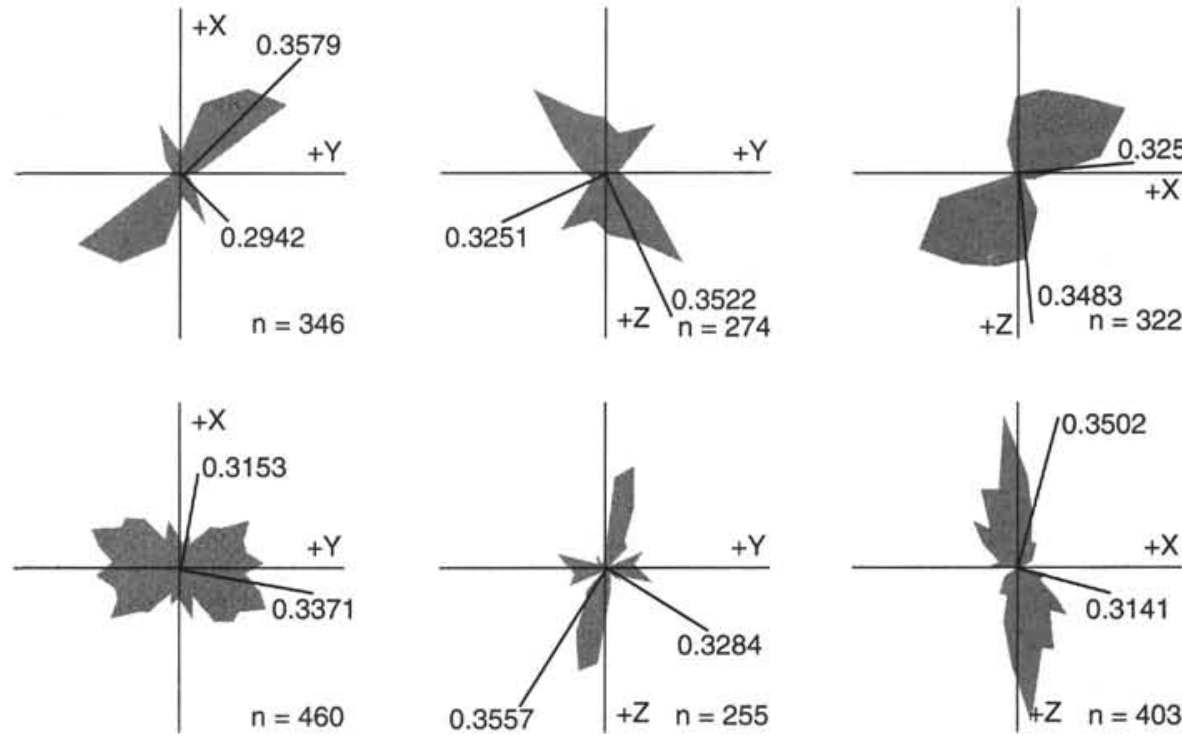

153-920D-15R-3,
$\begin{array}{lr}\text { Kmax } & 0.3561 \\ \text { Kmin } & 0.3468 \\ \text { Kmin } & 0.2971\end{array}$
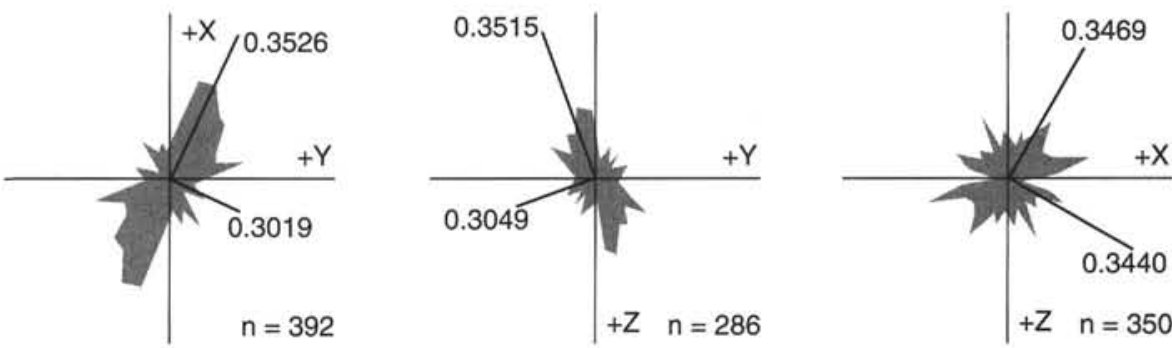

$\begin{array}{ll}\text { 153-920D-15R-6, } 76 \mathrm{~cm} \\ \text { Kmax } & 0.3552 \\ \text { Kint } & 0.3381 \\ \text { Kmin } & 0.3067\end{array}$

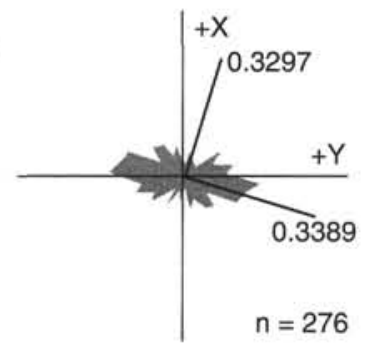

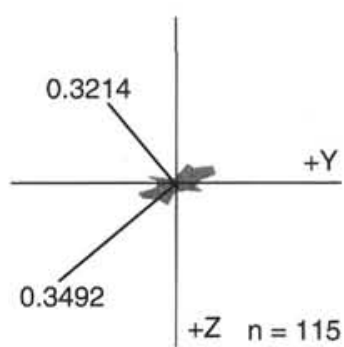

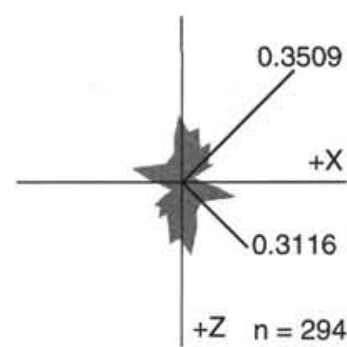

Figure 5. Rose diagrams showing the orientation of magnetite grains or grain clusters (see text for details) from petrographic analysis and apparent maxima and minima in susceptibility in three orthogonal thin sections. The orientation analyses are displayed as number of individuals within a $10^{\circ}$ window and are all displayed at the same scale. The apparent susceptibility maxima and minima are all shown at a common scale.

the larger sample set from Site 920 (Shipboard Scientific Party, 1995; Hurst et al., this volume). The strong correspondence of magnetite preferred orientation and AMS data in all three sections for Sample 153-920D-15R-3, $96 \mathrm{~cm}$, provides further support for this interpretation. In this sample, magnetite is predominantly located along the V2 vein boundaries. However, the overall orientation of magnetite clus- ters, and hence the V2 veins, in the $\mathrm{x}-\mathrm{y}$ plane is significantly steeper $\left(65^{\circ} \mathrm{dip}\right)$ than the orientation of the coincident V2 veins and composite foliation, in the same plane, $\left(\sim 30^{\circ}\right.$ dip $)$ determined at the hand specimen scale. As neither mesoscopic fabric element is near the dominant magnetic foliation in this plane, we tentatively suggest that the magnetic fabric may provide the best estimate of the volume-in- 
Table 3. Projected AMS ellipsoid maximum and minimum values in the three orthogonal sections.

\begin{tabular}{|c|c|c|c|c|c|c|c|c|c|c|c|c|}
\hline \multirow{2}{*}{$\begin{array}{l}\text { Core, section, } \\
\text { interval }(\mathrm{cm})\end{array}$} & \multicolumn{4}{|c|}{$x-y$ plane } & \multicolumn{4}{|c|}{$y$-z plane } & \multicolumn{4}{|c|}{$z$-x plane } \\
\hline & $K_{\max }$ & $\theta\left(^{\circ}\right)$ & $K_{\min }$ & $\theta\left({ }^{\circ}\right)$ & $K_{\max }$ & $\theta\left(^{\circ}\right)$ & $K_{\min }$ & $\theta\left({ }^{\circ}\right)$ & $K_{\max }$ & $\theta\left({ }^{\circ}\right)$ & $K_{\min }$ & $\theta\left({ }^{\circ}\right)$ \\
\hline 153-902D- & & & & & & & & & & & & \\
\hline $4 \mathrm{R}-2,51-54$ & 0.3372 & 150 & 0.3310 & 60 & 0.3466 & 135 & 0.3179 & 45 & 0.3391 & 55 & 0.3290 & 145 \\
\hline $14 \mathrm{R}-2,35-38$ & 0.3579 & 45 & 0.2942 & 135 & 0.3522 & 65 & 0.3251 & 155 & 0.3483 & 175 & 0.3255 & 85 \\
\hline $14 R-3,91-94$ & 0.3371 & 100 & 0.3153 & 10 & 0.3557 & 122 & 0.3284 & 32 & 0.3502 & 15 & 0.3141 & 105 \\
\hline $15 R-3,96-99$ & 0.3526 & 25 & 0.3019 & 115 & 0.3515 & 70 & 0.3049 & 160 & 0.3469 & 30 & 0.3440 & 120 \\
\hline $15 R-6,76-79$ & 0.3389 & 107 & 0.3297 & 17 & 0.3492 & 140 & 0.3214 & 50 & 0.3509 & 45 & 0.3116 & 135 \\
\hline
\end{tabular}

Note: The orientation of the maximum and minimum are reported clockwise from the $+x-a x i s$ in the $x-y$ plane, the $+y-a x i s$ in the $y-z$ plane, and the $+z-a x i s$ in the $z-x$ plane.

tegrated average dip $\left(\sim 65^{\circ}\right)$ of the subparallel V2 veins and crystalplastic fabric in this sample.

Where V2 veins are not well developed, the mesh-network magnetite may be the dominant factor controlling the shape of the magnetic susceptibility ellipsoid. Circumstantial evidence for the possible importance of serpentinization of matrix materials in determining the magnetic fabric is provided by the results from Sample 153$920 \mathrm{D}-14 \mathrm{R}-3,91 \mathrm{~cm}$. Although this sample has essentially no V2 veins, the projection of the AMS ellipsoid and the apparent cumulative magnetite dimensional long axes are both coincident with the crystal-plastic fabric in the $x-y$ plane. The magnetic anisotropy of Sample (153-920D-15R-6, 76-79 cm) may also reflect a contribution from serpentinization of fabric elements in the mesoscopic composite foliation, primarily the mesh-network magnetite. Few magnetite grains are visible in the thin sections, and the crystal-plastic foliation and V2 veins exhibit a large angular difference. These factors result in rose diagrams in which the cumulative magnetite long axes have smaller magnitudes than the other samples; however, there are clearly two planes in which magnetite has a preferred dimension distribution and approximates the apparent AMS ellipsoid in each of the planes. The orientation of the magnetite preferred fabric and projected susceptibility maxima in the $x-y$ plane apparently lies between the horizontal V2 veins and the composite foliation dip $\left(30^{\circ}\right)$.

Although the number of samples analyzed is small, we suggest that the late-stage, low-temperature serpentine \pm magnetite $V 2$ veins are the primary contributors to the AMS signature of the peridotites from Site 920. Magnetite associated with these veins occurs as highly elongate grain clusters either within the vein material (perpendicular to the vein boundaries) or along the vein boundaries (oriented subparallel to the boundaries). Within the veins there are small trails of magnetite that appear as vein-boundary perpendicular continuations of the mesh-texture trails, suggesting that the veins developed by veinboundary orthogonal opening, which postdated mesh-texture formation. Individual magnetite grains (where discernible) within the veins are almost exactly perpendicular to $k_{l}$ of the susceptibility ellipsoid; however, they are small and far less abundant than the larger magnetite grain clusters along the vein boundaries, which are subparallel to the $k_{l}$ direction. Additional occurrences of magnetite are thought to be less important than the V2 veins in determining the magnetic anisotropy. Magnetite in orthopyroxene pseudomorphs are equant in all three of the orthogonal thin sections for all samples. Magnetite grains formed in association with fracturing within chrome spinel grains are very limited, and hence are not a significant component of the overall magnetite in a sample and the associated AMS signature.

\section{CONCLUSIONS}

Although peridotites contain little to no primary ferromagnetic minerals, Site 920 peridotites have experienced extensive serpentinization and associated magnetite formation. The high average NRM intensity $(11.8 \mathrm{~A} / \mathrm{m})$ together with a high average Koenigsberger ratio $(\mathrm{Q}=4.7 \pm 1.5)$ indicate that, at least locally, these serpentinites could have a significant contribution to magnetic anomalies. The consistent stable inclinations determined for Site 920 samples, which differ from predicted normal polarity inclinations for the area, could indicate a bulk rotation of the entire massif. Hence, paleomagnetic inclination data could be used in structural reorientation studies (Hurst et al., this volume). However, in the light of the AMS characteristics described here, it is necessary to first fully understand and characterize the AMS and its effect on remanence acquisition before confident reorientation studies can be accomplished.

Serpentinized peridotite samples from Site 920 are characterized by high (but variable) degrees of magnetic anisotropy. The majority of samples exhibits oblate susceptibility ellipsoids $(<20 \%$ are neutral or prolate). Three-dimensional orientation analysis of magnetite grain clusters shows there to be a reasonable correlation between the cumulative long-axis orientation maximum direction and the apparent susceptibility ellipsoid $k_{l}$ direction in three orthogonal planes. The angular difference between the two features is typically $5^{\circ}-15^{\circ}$ in each of the orthogonal sections. The magnetic susceptibility ellipsoid is clearly anisotropic in all samples regardless of the rock fabric development. The large AMS in these serpentinized peridotites is believed to result from distribution anisotropy of magnetite formed during serpentinization. There are two dominant occurrences of magnetite (1) a pervasive mesh network of magnetite grains associated with serpentinization of silicate minerals defining the high-temperature crystal-plastic foliation, and (2) magnetite in association with later low-temperature serpentine (V2) veins. The crystal-plastic foliation and V2 veins are commonly subparallel to each other, although the angular relationship between the two can be as much as $90^{\circ}$; both are developed to varying degrees throughout the core. Magnetite within $\mathrm{V} 2$ veins is considered to be the volumetrically dominant occurrence, and hence controls the AMS in the majority of the cores. In regions where $\mathrm{V} 2$ veins are strongly developed, the magnetic foliation $\left(k_{l}\right.$ and $k_{2}$ directions) are subparallel to the veins and the maximum susceptibility axis $\left(k_{3}\right)$ is approximately perpendicular to the veins. However, in regions with few V2 veins, there is still a strong magnetic anisotropy. This anisotropy is presumably the result of a preferred orientation of mesh-texture magnetite, suggesting that serpentinization of the fabric elements defining the high-temperature crystal-plastic foliation may also contribute to the AMS signal.

\section{ACKNOWLEDGMENTS}

This work was supported by JOI/U.S. Science Support Program grant 153-20822b. We are indebted to Dennis Kent at LamontDoherty Earth Observatory and Kenneth Verosub at the University of California at Davis for the use of their magnetics laboratories. We thank Jeffrey Karson for his valuable contributions to the project.

\section{REFERENCES}

Bina, M.M., and Henry, B., 1990. Magnetic properties, opaque mineralogy and magnetic anisotropies of serpentinized peridotites from ODP Hole 670A near the Mid-Atlantic Ridge. Phys. Earth Planet. Inter., 65:88103.

Cande, S.C., and Kent, D.V., 1992. A new geomagnetic polarity time scale for the Late Cretaceous and Cenozoic. J. Geophys. Res., 97:1391713951.

Cannat, M., Karson, J.A., Miller, D.J., et al., 1995. Proc. ODP, Init. Repts., 153: College Station, TX (Ocean Drilling Program). 
Detrick, R., Honnorez, J., Bryan, W.B., Juteau, T., et al., 1988. Proc. ODP. Init. Repts., 106/109: College Station, TX (Ocean Drilling Program).

Hargraves, R.B., Johnson, D., and Chan, C.Y., 1991. Distribution anisotropy: the cause of AMS in igneous rocks? Geophys. Res. Lett., 18:2193-2196.

Hrouda, F., 1991. Models of magnetic anisotropy variations in sedimentary thrust sheets. Tectonophysics, 185:203-210.

Jelinek, V., 1981. Characterization of the magnetic fabric of rocks. Tectonophysics, 79:63-67.

Johnson, H.P., and Pariso, J.E., 1993. Variations in oceanic crustal magnetization: systematic changes in the last 160 million years. J. Geophys. Res., 98:435-445.

Kirschvink, J.L., 1980. The least-squares line and plane and the analysis of palaeomagnetic data. Geophys. J. R. Astron. Soc., 62:699-718.

MacDonald, W.D., and Ellwood, B.B., 1988. Magnetic fabric of peridotite with intersecting petrofabric surfaces, Tinaquillo, Venezuela. Phys. Earth Planet. Inter., 51:301-312.

McFadden, P.L., and Reid, A.B., 1982. Analysis of paleomagnetic inclination data. Geophys. J. R. Astron. Soc., 69:307-319.

Potter, D.K., and Stephenson, A., 1988. Single-domain particles in rocks and magnetic fabric analysis. Geophys. Res. Lett., 15:1097-1100.
Shipboard Scientific Party, 1995. Site 920. In Cannat, M., Karson, J.A. Miller, D.J., et al., Proc. ODP, Init. Repts., 153: College Station, TX (Ocean Drilling Program), 45-119.

Stacey, F.D., and Banerjee, S.K., 1974. The Physical Principles of Rock Magnetism. Dev. Solid Earth Geophys., 5: New York (Elsevier).

Stephenson, A., 1994. Distribution anisotropy: two simple models for magnetic lineation and foliation. Phys. Earth Planet. Inter, 82:49-54.

Tarling, D.H., and Hrouda, F., 1993. The Magnetic Anisotropy of Rocks: London (Chapman and Hall).

Toft, P.B., Arkani-Hamed, J., and Haggerty, S.E., 1990. The effects of serpentinization on density and magnetic susceptibility: a petrophysical model. Phys. Earth Planet. Inter., 65:137-157.

Date of initial receipt: 17 August 1995

Date of acceptance: 22 March 1996

Ms 153SR-041 

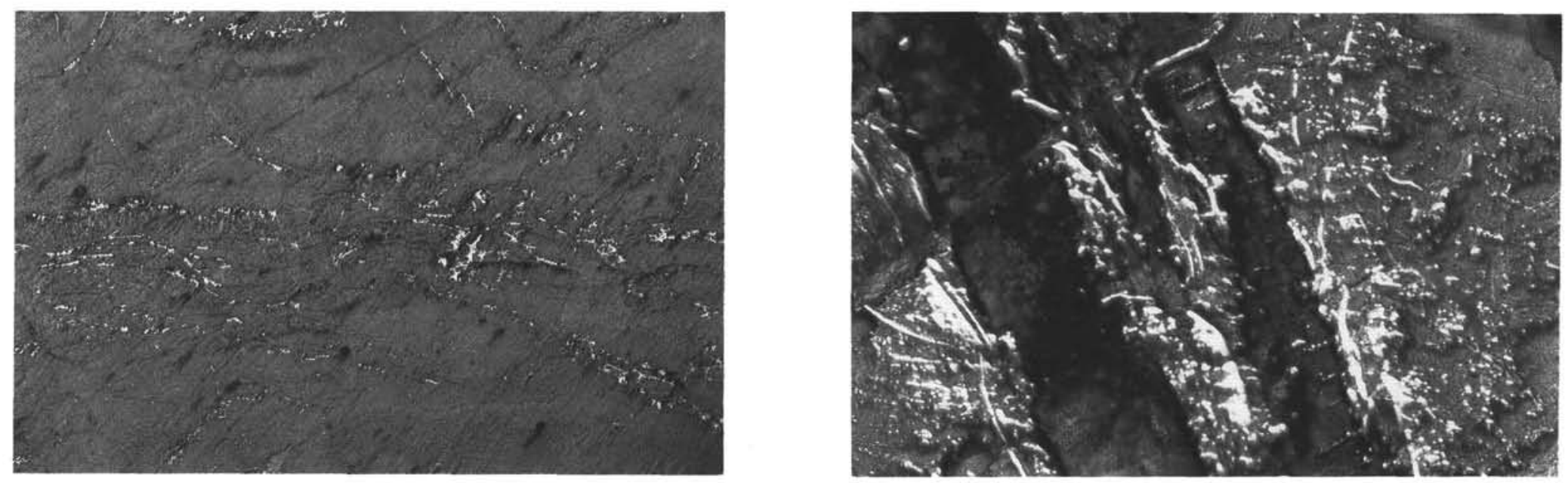

3

4
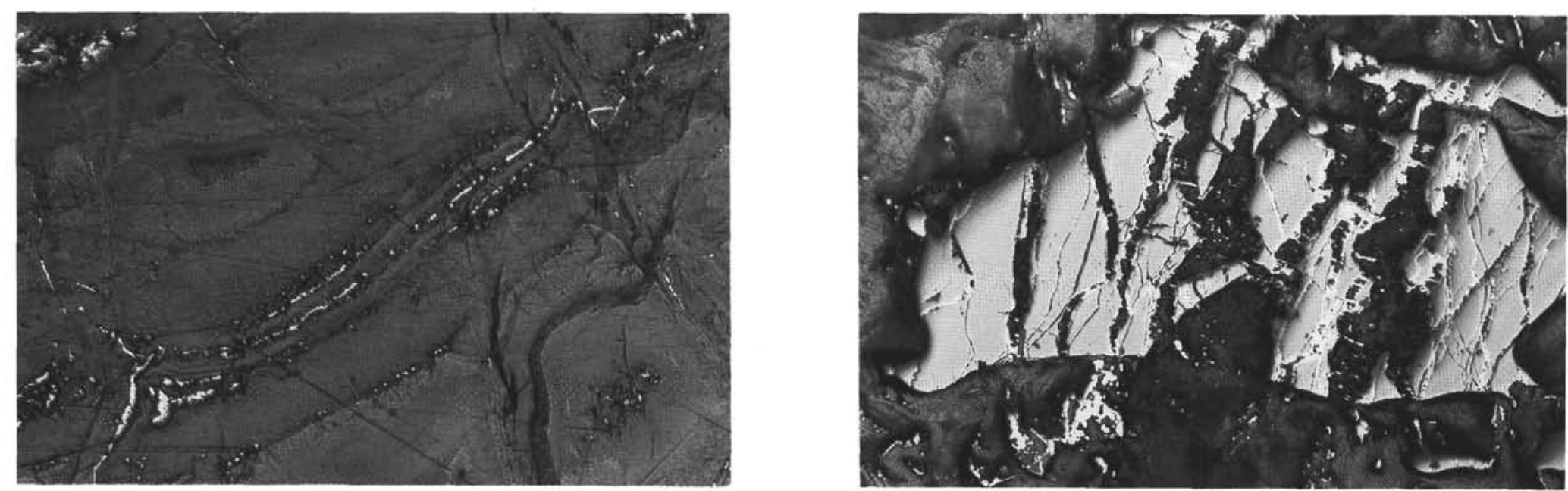

Plate 1. Photomicrographs showing magnetite occurrences in Site 920 serpentinites. 1. Sample 153-920D-14R-1, $35 \mathrm{~cm}, \mathrm{y}-\mathrm{z}$ plane. Magnetite occurs as small equant grains within pseudomorphs of orthopyroxene throughout the serpentinized peridotites. 2. Sample 153-920D-14R-1, $35 \mathrm{~cm}, \mathrm{x}-\mathrm{y}$ plane. Within the V2 serpentine veins, magnetite occurs as small, highly elongate, grain clusters oriented approximately orthogonal to the vein boundaries. 3. Sample 153-920D-14R-3, $91 \mathrm{~cm}, \mathrm{z}-\mathrm{x}$ plane. Along the boundaries of V2 veins, magnetite is abundant as large elongate clusters that are approximately parallel to the vein boundaries. 4. Sample 153-920D-15R-6, $76 \mathrm{~cm}, x-y$ plane. Magnetite forming along small fractures within chrome spinel minerals. Field of view in each photograph is approximately $2 \mathrm{~mm}$. 